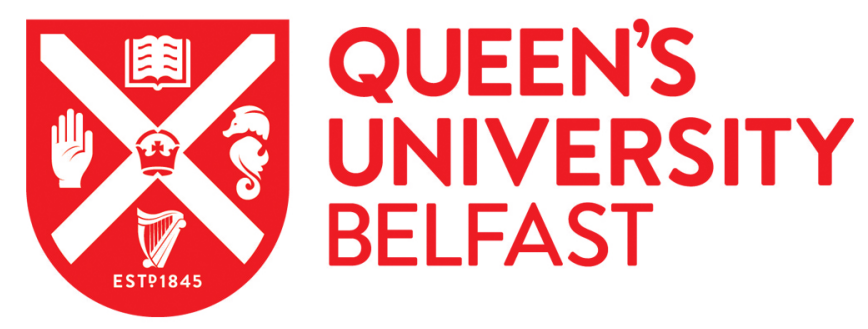

\title{
Enabling Others in Social Work: Reflexivity and the Theory of Social Domains
}

Houston, S. (2015). Enabling Others in Social Work: Reflexivity and the Theory of Social Domains. Critical and Radical Social Work, 3(2), 245-260. https://doi.org/10.1332/204986015X14302240420229

Published in:

Critical and Radical Social Work

Document Version:

Peer reviewed version

Queen's University Belfast - Research Portal:

Link to publication record in Queen's University Belfast Research Portal

Publisher rights

Copyright 2015 Policy Press.

This work is made available online in accordance with the publisher's policies. Please refer to any applicable terms of use of the publisher.

\section{General rights}

Copyright for the publications made accessible via the Queen's University Belfast Research Portal is retained by the author(s) and / or other copyright owners and it is a condition of accessing these publications that users recognise and abide by the legal requirements associated with these rights.

Take down policy

The Research Portal is Queen's institutional repository that provides access to Queen's research output. Every effort has been made to ensure that content in the Research Portal does not infringe any person's rights, or applicable UK laws. If you discover content in the Research Portal that you believe breaches copyright or violates any law, please contact openaccess@qub.ac.uk. 


\title{
Enabling Others in Social Work: Reflexivity and the Theory of Social Domains
}

\begin{abstract}
This paper sets out a framework to structure reflexivity in social work practice. Based on the thinking of the sociologist, Derek Layder, it comprises five domains that impact on the individual and social life, namely: (i) psycho-biography - referring to a person's unique experience throughout the life-course; (ii) situated activity - highlighting the impact of every day social interaction; (iii) social settings - addressing the role of organizations in social life; (iv) culture - covering the influence of attitudes, beliefs, tastes and ideas on symbolic meaning; and ( $v$ ) politico-economy - alluding to the ramifications of political and economic forces on people's lives. It is contended that power circulates throughout each domain as an enabling and constraining force. The paper then outlines a process for using the reflexive framework in 'enabling' activities such as practice learning, supervision, mentoring and coaching. By applying the framework in these contexts, it is argued that social workers can reflect critically on their role and develop emancipatory forms of practice.
\end{abstract}

Key words: reflexivity, power, enabling others, emancipation

\section{Introduction}

The notion of reflexivity has attracted much interest in the academic and applied fields. In the social sciences, there are four main perspectives which attempt to throw light on the subject. The first addresses the way in which a body of knowledge can refer back to itself in a critically, interrogative manner (Woolgar, 1988). For example, not only does sociology examine social relations, institutions and structures in a questioning way, but it also takes a step back and reviews its own core assumptions concerning these areas. In other words, reflexivity in this sense initiates a sociology of the discipline's own knowledge base.

The second notion of reflexivity is chiefly promulgated in ethnomethodology (Garfinkel, 1991) and symbolic interactionism (Mead, 1967), two central theories in sociology that emphasise how meaning is socially produced through social performance, communication and interaction. According to these theories, social life is not essentially governed by wider social forces but rather shaped by social actors reflecting and talking about their everyday actions. Reflection and talk then become constitutive: that is, they make the social world happen and shape it. Used in this context, reflexivity is a tool that exposes actors' knowledge, talk and practice to critical analysis rather than taking these areas for granted or seeing them as representing some objective truth.

This previous approach can be contrasted with a third view of reflexivity which is couched within an understanding of contemporary society. Here, it is argued that the relentless modernization of social life enables individuals to reflect on their existence and change or re-fashion themselves according to desired life-projects. Beck (1992) refers to this process 
as reflexive modernization. It is exemplified in the individual's reflection on her lifestyle, identity, choices and opportunities. The aim is to promote self-actualization.

Fourthly, reflexivity has been interpreted as a means of furthering an emancipatory project (Humphries and Truman, 1994). More specifically, it has been used to show how knowledge, norms, roles, social positions, and discourses intertwine with power and how they are also influenced by wider social domains (such as various types of institution) to enable or constrain life outcomes. Applied often within qualitative research, and drawing on critical social theory, this version of reflexivity examines the impact of personal and social characteristics (for example, gender, sexuality, race or class) and the socio-cultural world on meaning, narrative, knowledge production and social action. In all of this, the intention is to shed light on how individuals are constrained by structural contradictions and cleavages, limited life opportunities, status injustices and social divisions.

The literature on reflexivity in social work connects to some degree with these perspectives. Before exploring this connection, it is important, firstly, to echo Sheppard's view (1998) that social work has its own social work-specific meanings of the term. As evidence of this point, D'Cruz et al. (2007) highlight an additional understanding of reflexivity in social work not covered above: one where the role of self, cognition, and emotion are subjected to analysis. For instance, it is posited that social workers need to reflect on their anxiety, ambivalence and fear, especially in situations where a care and control function must be exercised or a statutory remit imposed. Importantly, for these authors, reflexivity in social work is a multifaceted concept and linked with cognate terms such as critical reflection, reflectivity and critical reflectivity. In the literature, these terms are sometimes conflated with reflexivity or used interchangeably with it, making definitional clarity, not to say consensus, inherently problematic (Kessl, 2009; De Cruz et al., 2007).

Taylor and White (2000) approach the notion of reflexivity much like the one articulated in the second perspective in the typology. Thus, they argue that social workers need to critically appraise how they socially construct their knowledge claims and practices. This involves scrutinizing tacit assumptions in social work concerning, for example, the causation of child abuse or how mental illness is viewed and categorized. Within this stance, meaning is problematized and relativized. Furthermore, the authors draw on ethnomethodological techniques, such as conversation analysis, to show how social work knowledge is contingent and malleable. They also utilize the fourth definition of reflexivity, arguing that social workers' meaning-making activities are embroiled in power-saturated discourses.

A different stance on the topic is adopted by Ferguson (2001) and Fook (2000). They draw on the reflexive modernization thesis (highlighted above) to argue that reflexivity enables service users to consider their potential life trajectories, the risks they may be exposed to in making personal changes, and ways of developing intimacy with others. Service users, according to Ferguson, can take a more active role in defining their needs and should be afforded opportunities to engage in life-planning. Reflexivity, in this context, opens up a 
greater democratization of relationships, particularly in the domestic sphere, as people become increasingly self-aware. Yet, as Garrett (2004) has argued, this use of reflexivity may not give sufficient attention to asymmetrical power imbalances between actors nor the structural contradictions curtailing the expression of individualized life projects.

Butler et al. (2007) describe how the fourth perspective on reflexivity was applied to social work practice. These authors challenge social work's preoccupation with evidence-based practice, arguing that professional intervention is more embedded in process than evidential outcomes. This is a process that requires the negotiation of meaning in an overall context of uncertainty. The authors cite the example of working with women marginalised by their experience of mental ill-health. Enabling the women to debunk disabling narratives of self - which have been inscribed through socially constructed positions, roles and norms necessitates that social workers are reflexive about how power shapes subjective experience. Feminist theory provides the lens through which such reflexive, emancipatory practice is viewed. This stance chimes with Fook and Askeland's (2006) perspective on reflexivity as the capacity to identify, not only one's own influence on events, but also that of the socio-cultural world.

In this paper, I adopt the fourth understanding of reflexivity to develop a reflexive framework for social work practice. This stance on reflexivity enables social work practitioners to be sensitive to the impact of power on themselves and service users. It also helps them reflect on how various personal and social spheres have shaped meaning and biography. Without this vital understanding, it is hard to see how anti-oppressive practice can materialize in any meaningful way. However, at this juncture, it is important to state that the four types of reflexivity should not be viewed as mutually exclusive nor disconnected. Even though the presented framework draws essentially from, and thereby privileges, emancipatory reflexivity, it is clear that social workers must reflect critically on their own social work knowledge base (utilizing the first definition). Moreover, they need to examine how they carry out every day, taken-for-granted practices that are embroiled in symbolic interaction with service users and other professionals (adopting the second definition), and how their practice can facilitate important changes in life trajectories (utilizing the third definition).

Below, I describe how the reflexive framework was developed and then illustrate it. Following this explication, the paper then outlines a structured process for using the framework in various enabling contexts in social work. By this I mean those contexts where social workers are required to use reflexivity with an enabling 'other', to examine their practice with service users. Such contexts include, inter alia, practice learning, where a student on placement reflects with the help of a designated practice teacher; formal and informal supervision where a social worker and line manager explore facts and feelings pertaining to assessment; or mentoring, where a novice social worker is helped by a more experienced colleague to review her use-of-self in a practice situation. It is vital to place 
reflexivity within this relational context as internalised thinking, without the benefit of communicational exchange, might succumb to bias.

\section{Outline of the Reflexive Framework}

The framework draws primarily on Layder's (2006) theory of social domains. This theory outlines the stratified, or layered, nature of social life and how it shapes social action. In doing so, it provides a conceptually rich understanding of how social life is structured into various micro, mezzo and macro contexts marrying the psychological and sociological dimensions of our being. So far, Layder's theory has not been used for the purpose of developing reflexivity in social work practice or even applied more widely.

In order to address this gap, let us consider Layder's contention that there are four domains shaping social life, namely: (i) psycho-biography referring to a person's unique existence throughout the life-course with all its critical events such as loss, change and crisis; (ii) situated activity which involves everyday social interaction including exchanges within families; (iii) social settings which encompass institutions and organizations such as workplaces, educational settings and bureaucracies; and (iv) contextual resources which denote the resources or types of capital (economic, symbolic, educational and cultural) which are distributed asymmetrically to social actors depending on their position, rank and role in society.

For Layder, these domains are 'interconnected through social relations of power which are also stretched out over time and space' (p. 274). In this formulation, power is multidimensional, ubiquitous and omnipresent in every encounter and setting. As regards the first two domains, power tends to be personal and intersubjective whereas in the second two, it takes on more of a systemic or structural influence leading to the reproduction of social norms, discourses and positions. Power, in each of these domains, gives rise to objective forms of constraint and enablement and is linked crucially to the array of resources at a person's disposal.

Importantly, for Layder, these domains are interlocking and mutually-dependent. For example, the lack of economic resources in social life may impact deleteriously on the domain of situated activity leading to inter-personal tensions between people. That said, the domains also possess their own distinct characteristics. The domain of social settings, for instance, focuses on institutional processes defining acceptable group behaviour. Hence, working in a bureaucracy requires social actors to conform to stipulated employee expectations. Such requirements are unique to this domain but nevertheless reverberate on a person's psycho-biography and social interaction.

By way of comment, Layder's theory provides a very helpful understanding of social life and therefore has value in illuminating the emancipatory kind of reflexivity described earlier in our typology. That said, it requires some revision to make it apt for reflexive social work. 
Fundamentally, I query Layder's attempt to clamp together the spheres of 'culture' and 'economy' under his fourth domain and reduce them solely to various forms of resource. Contra Layder, it is vital to see these areas as distinct domains in their own right, with their own properties, even though they are indelibly linked (Archer, 1996). Regarding the impact of culture, social work has to operate increasingly in a multi-cultural environment where the ever present dangers of racism, sectarianism, xenophobia and ethnocentrism are frighteningly evident. In this world, cultural meanings are not homogeneous - yet the pressures for assimilation all too real particularly in the context of growing anxieties about immigration. Developing a culturally-sensitive social work requires that culture is seen as a discrete domain in its own right. It cannot be reduced only to cultural resources as culture also confers symbols, artefacts, norms and beliefs that shape meaning irrevocably (Macionis and Plummer, 2012).

In respect of the economy, social workers in the western world are increasingly subject to neo-liberal welfare ideologies promulgating individualism, commodification, retrenchment, and the personalisation of services (Ferguson, 2008). These trends emanate from political and economic imperatives within modern States and have a formative bearing on the lives of service users. So, it is vital to make this influence explicit by creating a distinct domain of politico-economy. In making these changes, though, we should not lose sight of Layder's key idea that both the culture and economy either provide or withhold much needed resources.

Lastly, I have attempted to add some theoretical flesh to the schematic bones of each domain making them relevant for reflexive, social work practice. This adaptation is by no means exhaustive or comprehensive. Instead, it highlights a number of purposively selected constructs underpinning each domain that may have a central importance for social work practice. (The relevance and significance of these constructs will be reviewed in the research referred to earlier). Layder's re-worked framework is presented diagrammatically and summarized below (see Figure 1).

\section{PLACE FIGURE 1 HERE}

The domain of psycho-biography

This domain highlights a person's life-course as it progresses along a trajectory through time and space in the social world (Green, 2010). In other words, it establishes a person's unique biographical and embodied history as it has unfolded from birth onwards charting the significance of various transitions from childhood, through adolescence, to adulthood and then the experience of later life. At each point of transition there may be psycho-social challenges to face and resolve (Sudbery, 2010). This domain also looks at how significant events have impacted on the person psychologically. What is of concern here is the effect of loss, change, ageing, illness (mental and physical), disability, sensory impairment, psychological trauma, crisis, estrangement, re-union, and opportunities for growth and development. Throughout the life-course, we are also socially positioned according to our 
race, class, age, sexuality, religion and gender. These categories are socially constructed by powerful discourses in society (Butler, 1990).

Within this domain, the construct of narrative is highly significant (Baldwin, 2013). This refers to the auto-biographical story we build up about ourselves, others, our past and imagined, future lives. For some people, such stories can be oppressive recounting the misuse of power by significant others while contrasting narratives can depict positive adaptations to challenging circumstances. All in all, narratives integrate a person's life history around a core, inner identity. Furthermore, narrative is a tool for bringing about therapeutic change in social work. A person can reach a more empowered stance in her life through telling and reinterpreting her story to an empathetic individual (White and Epston, 1990). In this process, people need to externalise and distance themselves from their disabling narratives - stories that perpetuate shame, poor self-esteem and self-disrespect. By doing so, they can then formulate alternative stories about themselves that lead to change or adaptation. Narrative is therefore a means to a therapeutic end.

This domain can also be used by social workers to make sense of loss and change in a person's life-course and its impact on her identity. For example, social workers (out of necessity) need to attend to the procedural and practical requirements for moving an older person from supported care in the community to residential accommodation. However, by drawing on the domain of psycho-biography, the importance of the psycho-social aspects of the transition are brought into a sharper focus. Thus, for some older people there will be a loss of independence and also a forfeiture of role, competence and meaningful activity that could ostensibly have an impact on mood and general well-being. Furthermore, the notion of psycho-biography underscores the salience of reminiscence therapy or life-history work. This type of intervention can counteract depression and loneliness, and enhance relationships between carers and relatives with dementia (Chiang et al, 2010).

\section{The domain of situated activity}

This domain focuses on what happens in everyday, informal, social interaction involving dyads or small groups of significant others including families. Such interaction reflects the truism that we are social beings 'all the way through' (Mead, 1967). When we first come into the world we are deeply connected to our caregivers. As we mature, we develop a sense of our individuality (Winnicott, 1991). Yet, even though we move towards greater independence, our relationship with significant others continues to provide meaning, social support, comfort and a sense of belonging. Conversely, relationships can break-down through negative projections, inter-personal power struggles, misunderstandings and unmet care and control needs. Whatever the outcome, though, people need to be seen in the context of their most intimate, close relationships (for example, peers, family, and friends). This point is affirmed in ecological and systems thinking. One leading exponent of these perspectives, Urie Bronfenbrenner (1979), argues that systems of rich and varied personal interaction play a vital role in human growth and development. 
Given what has been said, attachment theory adds theoretical substance to this domain (Howe, 2011). Here, it is posited that children require a secure base with their carers to enable them to explore their social worlds confidently and subsequently develop cognitive, emotional, social and linguistic skills. In other words, a secure attachment assists people to mature into competent, responsible adults who are fully open to the challenges they may face in various settings. The corollary to this is children who experience impoverished care of some sort and the insecurity it may engender. As a consequence, exploratory actions might be compromised and human development thwarted. Furthermore, it is suggested secure children most likely develop positive inner working models whereas insecure children are at risk of succumbing to unconfident, anxious personalities. It is important to state at this point that attachment extends well beyond the spheres of childhood and adolescence into the remaining stages of the life-course (Howe, 2011).

If 'relationship' is central to positive identity-formation, then it is incumbent on social workers to place it at the heart of their practice (Ruch et al., 2010). Warm, consistent relationships play a formative role in nurturing a child's psychological and social development (Golding, 2000). Hence, when making care plans for a child who requires substitute care (as a result of past traumatic experiences), social workers and carers need to use this domain to tune into his emotional needs. More than that, they need to consider how they will provide a secure base, foster attunement, effect a sense of relational belonging, and engender interactive repair (when relationships breakdown). As Golding argues, sensitive substitute parenting pivots on building relationships with the child. In addition, through the use of eco-maps, genograms and other tools, social workers can assess the quality (or impoverishment) of a child's relationships and social networks outside the home (Parker and Bradley, 2010). What is vital here is the density or paucity of these relationships, the presence of criticism within them, whether they are reciprocal and how much support they provide to the child (Tracy and Whittaker, 1990).

\section{The domain of social settings}

Most of us interact with and are affected (in some way) by formal organizations and institutions - or the domain of social settings. These include the workplace, various bureaucracies with which we come into contact (such as Government bodies), schools we have attended, universities we may have graduated from and possibly care institutions in which our older relatives may now reside. As social workers, we may visit children living in residential care or secure accommodation. Other social workers may have been involved in the compulsory detention of adults in a mental institution.

Many of these social settings, according to Layder (2006), have a distinct organisational shape and form. For instance, within them people often relate to one another in a formal and tightly structured manner. This style of relating can be seen typically in bureaucracies such as social services. Moreover, actors within social settings are expected to adopt predefined social relations, positions and practices. Hence, social workers in case conferences 
are expected to relate to other members of the meeting in a professional manner and adopt certain practices such as conveying their assessment of need, risk and required resources. Social relations within the conference are invariably clearly defined and hierarchical in nature. The chair of the conference may show her authority and exercise power over decision-making. These relations, positions and practices are socially reproduced over time and embedded in procedural codes and tacit rules. According to Layder, they are 'the reproduced outcomes of past social activities that influence behaviour in the present' $(p$. 280).

Many contemporary social settings are further characterised by efficiency, predictability, quantitative measures, technology and bureaucracy (Ritzer, 2004). In social work, efficiency is shown in the way claims on the service are processed expeditiously in order to retain a capacity to assess new referrals. Predictability occurs when social workers adhere to strict procedures dictating how and when actions are to be performed. A fixation on quantity is manifest in managerial reviews of contract volumes and statistical outputs. Technology is reflected in computerised assessment frameworks, the electronic turn in human welfare and the move towards paperless records (Garrett, 2009). Lastly, bureaucracy is revealed in specialisation, hierarchy, technical competence, impersonal relations and formal written communication. What is more, the contemporary audit culture continues to use bureaucracy as a primary tool for organisational improvement and social care governance.

Social workers can use this domain as a sensitising concept to examine how bureaucracy helps or hinders their role and practice. It encourages them to examine the balance between administration and face-to-face interaction with service users and take action when the former is notably disproportionate. As part of this inquiry, the degree of professional discretion can be examined as practice can sometimes be curtailed by procedural mandates (Payne, 2011). Furthermore, it is important to review how different social care organisations (working in the community, voluntary, statutory and private sectors) diverge in role, structure, and function and how this effects inter-agency and multidisciplinary communication. Organisational life is also characterized by change and the stress it brings. Hence, it is important to reflect on how this change impacts on role and function and the delivery of services. Lastly, the domain of social settings provides a lens for viewing how the organisation affects service users. To what extent is it perceived as cold, detached and impersonal?

\section{The domain of culture}

\section{The domain of politico-economy}

This domain encompasses the combined effects of the State, the judiciary, the institutions of Government and the economy. It is fundamentally concerned with the material reproduction of society through the steering mechanisms of power, administration and money. What chiefly defines this domain is the economic doctrine of neo-liberalism: the 
contemporary expression of capitalism that has been adopted in most western States to varying degrees (Steger and Roy, 2010). Its chief supporters maintain that the consumerist, free-market (which should independent of State interference and regulation) leads to sound economic performance, market stability, and overall gains in wealth over time. Neoliberalism is also fundamentally expressed in public policies such as the deregulation of the economy, the liberalisation of trade and the privatisation of State-owned welfare and enterprise.

However, two central problems flow from neo-liberalism: commodification and inequality (Therborn, 2013). Both involve the (mis)use of systemic power and have implications for social work (Ferguson, 2008: Garrett, 2009). Commodification refers to the way in which various aspects of life are turned into commodities or things for sale. When commodification occurs in an unbridled way, market values colonize social life. People are no longer subjects but rather units of production whose labour is bought and sold without sentiment. In short, people become de-personalised objects. More than that, important areas of life, such as education, become a product to be sold as opposed to a way of developing people. Commodification also ensures that people in receipt of welfare services are drawn into market forces: means-tested benefits and targeted provision being two examples. As regards the second area, that of inequality, Layder (2006) argues that material resources under neo-liberalism are unevenly distributed and aligned according to personal and social categories such as age, social class, ethnicity, gender, disability and occupational status. In the UK and USA, for example, income inequality is increasing (Wilkinson and Pickett, 2010). Those designated as the 'poor' have notably fallen behind average earnings while the richest have progressed well beyond this level.

This domain poses a number of central questions for social workers: how do they respond to service users facing poverty, inequality and discrimination? To what extent do they engage in welfare rights, advocacy, negotiation and respectful challenge in support of service users? Is unmet need highlighted to senior managers within the organisation? Is material inequality factored into assessments and viewed as a key cause of problems such as poor mental health and delayed child development? How can social workers confront commodification? Such questions are predicated on the reality that social work is situated between the individual and society, between those who have power, and those who are excluded.

\section{Using the Reflexive Framework in an Enabling Process}

We are now in a position to consider how these domains can be used within an enabling process to foster emancipatory reflexivity. In this process, I contend there are five stages of reflexive inquiry (see Figure 2 below). These stages build up, cumulatively, to deepen the participants' understanding of themselves, their role, and the needs of service users. The intention is therefore to apply them sequentially. What makes this reflexive process unique is its centre-point: the particular rendition of the domains based on a re-worked version of Layder's theory of the person-in-society. For the purpose of clarification, the terms 
'supervisor' (referring to a team leader, practice educator or mentor acting as an enabler) and 'supervisee' (alluding to a student or social worker whose practice is being developed) have been appropriated to designate the key actors involved in the enabling process.

\section{PLACE FIGURE 2 HERE}

Stage one - the supervisor and supervisee apply the framework separately to their own life experience

In this initial stage, the supervisee and his supervisor consider separately how each of the domains have impacted on their lives, outlooks, beliefs, purposes and ambitions - and crucially, their view on social work as a helping process. In this undertaking they consider their unique psycho-biographies, the narratives shaping their stories, their progression through the life-course and how these areas have been shaped by powerful discourses. The role of emotion in personal experience, arising from attachments to significant others, should also be considered. In addition, both should consider how organisations, culture and the politico-economy have moulded their perspectives and outlook. This stage is designed to develop insight and inner awareness, reveal blind spots or occluded bias. Arguably, for social workers to maximise their use-of-self, spontaneously, they require such inner knowledge.

Recording thoughts and feelings in a reflexive diary, in this and subsequent stages, should help to capture important themes. This is an important undertaking as the supervisee (or supervisor) may have experienced trauma in their past lives. Potentially, this could resonate with a service user's experience to the point of unhelpful over-identification. Or, it may be that the supervisee has experienced a secure and stable upbringing in which case it may be more of a challenge to develop accurate empathy with a service user whose early experience has been marked by loss and change.

This initial stage may present as a challenge to both parties, particularly if they work in an organisational setting where bureaucratic and procedural imperatives militate against reflexivity. Not having the time to engage in such introspection, because of unremitting practice demands, poses a formidable barrier to this kind of activity. Consequently, the organisation has to support reflexivity as a time-honoured undertaking in its own right. As Thompson (2006) argues, though, this commitment has to be part of a wider learning culture that embraces continuing professional development.

Stage two - the supervisee and supervisor consider how the domains shape their interaction in supervision

In this second stage, the actors explore together how the domains influence their interaction in the enabling process. They may well have experienced very different psychobiographies. What is more, it could be that they contrast markedly in their respective personal and social attributes. For instance, there could be a gender and class difference. 
Moreover, they could look at the world through divergent cultural lenses. The supervisor might come from an ethnic minority background and symbolically hold a world view that is foreign to that of the supervisee's. Importantly, how does this affect the way they relate in supervision, what issues may it create, what potential misunderstandings may it evoke? Supervisors also appropriate distinctive styles of enabling. In this context, Hawkins and Shohet (2006) refer to authoritative and facilitative styles of engagement. The former comprises prescriptive, informative and challenging interventions while the latter embraces cathartic, empowering and supportive statements. A supervisee, because of his distinctive psycho-biography, might find the former style intimidating.

Furthermore, how do events in the life-course impact on the supervisee's professional development needs? How do the domains shape the way the supervisor mentors or tutors? How is power utilized in the enabling process particularly if it contains an element of assessment? The organisational domain of social settings may well impose strictures on the enabling process. If so, what are they? In considering the impact of the organisational context, the actors recognise that the enabling process occurs within a multifaceted context (Morrison, 2001; Tsui, 2005): one involving not only the supervisee and supervisor, but also the service user, outside agencies and a wider cultural domain. Likewise, for Morrison and Wonnacott (2010), the enabling process is not confined to the enabling dyad of supervisor and supervisee, but is also imbricated with a range of stakeholders (service users, other staff). It is a complex process that seeks to implement a range of functions including management, support, mediation and development. 
Stage three - the supervisee and supervisor apply the framework to 'tune-in' to the service user's needs and plan the social work process

Building on the preceding stages, the actors jointly attempt to understand how the domains, and the power operating within them, have shaped a service user's life, meanings, perspectives, needs, experience and the risks they face or present. This means taking account of devalued characteristics and status injustices including acts of misrecognition (Fraser and Honneth, 2004). In particular it begs the question of how wider economic realities, such as the climate of austerity, have impacted on well-being? The domain of psycho-biography has a particular purchase here enabling the actors to reflect on the service user's unique narrative and whether rights and capabilities have been fostered or ignored.

This stage of reflexive inquiry involves a process of tuning-in to the service user's life in order to deepen accurate empathy, compassion and sensitivity and also to gain greater insight into how assessment, planning, intervention and evaluation should be structured. It should be remembered that 'tuning in' is a means to an emancipatory end. In this context, the framework addresses the psychological and social aspects of being. This is an important dualism as there can be a danger of privileging one of these spheres over the other when trying to identify causal factors (Munro, 2002).

Tuning in also involves exploring the legal and policy context shaping intervention. Taking account of this context means being aware of legal duties and powers particularly in child and family social work and in mental health social work. The legal and policy context introduces the care and control dichotomy implicit within social work and the need to maintain an appropriate balance between both sides, fraught as this may be. In all of this, we are reminded of the centrality of the service user in supervision (Morrison and Wonnacott, 2010).

Stage four - the supervisee and supervisor apply the framework to reflect on the former's interaction with the service user

In this stage, the actors examine how the domains affect the supervisee's interaction with the service user. A critical issue here is how the supervisee's gender, age, cultural background, race, religion and social class interface with the service user's different (or perhaps similar) profile in relation to these personal and social categories. Importantly, how are differences in power and cultural capital expressed? The supervisee may be white, middle class, and in her fifties. If she has to undertake a piece of therapeutic disclosure work with a young, male Muslim child, where sexual abuse is suspected, how will such differences influence how the work is planned? Reflective insights gained from stages one, two and three will need to be harnessed here to make sense of these interactional dynamics. It is also important to appraise how this interaction affects the implementation of the social work process. This stage facilitates anti-oppressive social work and multi-cultural sensitivity 
approaches to social work practice (Payne, 2014) which attempt to combat discrimination on grounds of race, age, gender, disability or sexual identity. It also underscores Doel's (2012) emphasis on the need to take account of contextual differences in case planning.

\section{Stage Five - Towards meta-reflexivity}

This is the final, cumulative stage in the reflexive process. Here, the insights gleaned from the preceding stages are brought together, examined, processed and synthesised. Practically, this might be approached by becoming very familiar with the content of the reflexive diaries, applying tentative codings to particular entries and then developing deeper themes at a higher level of abstraction. The focus of attention is on the preceding stages which have looked at how the domains influence the personal and professional self, enabling and being enabled, the service user's meanings and the nature of the social work process. By reviewing these antecedent stages, the supervisee and supervisor search for recurrent themes around the use of power, and the use of self in the practice arena. How does who we are, because of our background and range of social experience, shape how we carry out emancipatory social work practice with service users whose experience may differ radically from our own? Responses to this question come as a result of a process of metareflection, a process which integrates the insights from stages one to four.

\section{Conclusion}

This paper has outlined a framework to guide emancipatory reflexivity and an enabling process to ground it. Drawing from Layder's social theory, five core domains of influence on the person were described, namely: psycho-biography, situated activity, social settings, culture, and politico-economy. A brief, and by no means exhaustive, sketch of each domain was elicited making a number of connections with social work. It was argued that the domains commingle and power flows through them much like blood through capillaries. They cohere in complex ways to effect change in people's lives and also shape inner identity. The message being relayed here is that we are social beings shaped by a wider social context. Thus, it is to the 'social' we should look when attempting to reflect on human behaviour. Importantly, identity is a social construct forged primarily through the domain of situated activity and relationship. If we are to heighten our reflexive capacity, we must consider the different facets of the 'social' time and time again. Reflexivity must centre on the self as a domain-shaped construct. It must also take account of the enabling relationship, interaction with the service user and sensitivity to her needs. 


\section{References}

Archer, M. (1996). Culture and Agency: The place of culture in social theory. Cambridge: Cambridge University Press.

Baldwin, C. (2013). Narrative social work: theory and application. Bristol: Policy Press.

Beck, U. (1992). Risk society: Towards a new modernity. London: Sage.

Belsay, C. (2004). Poststructuralism: A very short introduction. Oxford: Oxford University Press.

Bourdieu, P. (1977). Outline of a theory of practice. Cambridge: Cambridge University Press.

Bronfenbrenner, U. (1979). The ecology of human development: Experiments by nature and design. MA: Harvard University Press.

Butler, A., Ford, D. and Tregaskis, C. (2007). Who do we think we are? Self and reflexivity in social work practice. Qualitative Social Work, 6(3), 281-299.

Butler, J. (1990). Gender trouble: Feminism and the subversion of identity. London: Routledge.

Chiang, K, Chu, H., Chang, H. (2010). The effects of reminiscence therapy on psychological well-being, depression, and loneliness among the institutionalised aged. International Journal of Geriatric Psychiatry, 25, 380-388.

D'Cruz, H., Gillingham, P. and Melendez, S. (2007). Reflexivity, its meaning and relevance for social work: A critical review of the literature. British Journal of Social Work, 37, 73-90.

Doel, M. (2010). Social work placements: A traveller's guide. London: Routledge.

Ferguson, H. (2001). Social work: Individualisation and life politics. British Journal of Social Work, 13(1), 41-55.

Ferguson, I. (2008). Reclaiming social work: challenging neo-liberalism and promoting social justice. London: Sage.

Fook, J. (2000). 'Deconstructing and constructing professional expertise', in Fawcett, B., Featherstone, B., Fook, J. and Rossiter, A. (eds.). Practice and research in social work. London: Routledge.

Fook, J. and Askeland, G. (2006). The 'critical' in critical reflection, in Fook, J. White, S., and Gardiner, F. (eds.) Critical reflection in health and social care. Maidenhead: Open University Press.

Fraser, N. and Honneth, A. (2004). Redistribution or recognition: A political-philosophical exchange. London: Verso. 
Garfinkel, H. (1991). Studies in ethnomethodology. London: Wiley.

Garrett, P.M. (2004). 'More trouble with Harry: A rejoinder in the "life politics" debate'. British Journal of Social Work, 34(4), 571-583.

Garrett, P.M. (2009). 'Transforming' children's services: Social work, neoliberalism and the modern world. Maidenhead: Open University Press.

Giddens, A. (2009) Sociology (6 $6^{\text {th }}$ ed.). Cambridge: Polity Press.

Golding, S. (2000). Attachment and development. Oxford: Oxford University Press.

Green, L. (2010). Understanding the life course. Cambridge: Polity Press.

Hawkins, P. and Shohet, R. (2006). Supervision in the helping professions ( $3^{\text {rd }}$ ed.). Berkshire: Open University Press.

Howe, D. (2011). Attachment across the life-course: A brief introduction. Basingstoke: Palgrave Macmillan.

Humphries, B. and Truman, C. (eds.) (1994). Re-thinking social research. Aldershot: Avebury. Inglis, D. (2012). An Invitation to Social Theory. Cambridge: Polity Press.

Jenkins, R. (2008). Social identity ( $3^{\text {rd }}$ ed.). London: Routledge.

Kessl, F. (2009). Critical reflexivity, social work, and the emerging European post-welfare states. European Journal of Social Work, 12(3), 305-317.

Layder, D. (2006) Understanding social theory. London: Sage.

Macionis, J. and Plummer, K. (2012) Sociology ( $5^{\text {th }}$ ed.). London: Prentice Hall.

Mead, G.H. (1967). Mind, self and society. Chicago: Chicago University Press.

Morrison, T. (2001). Staff supervision in social care. Brighton: pavilion Publishing.

Morrison, T. and Wonnacott, J. (2010). Supervision: Now or never. Reclaiming reflective supervision in social work. www.local.gov.uk/c/document_library/get_file?uuid.

Munro, E. (2002). Effective child protection. London: Sage.

Oko, J. (2011). Understanding and using theory in social work $\left(2^{\text {nd }}\right.$ ed.). Exeter: learning Matters.

Parker, J. and Bradley, G. (2010). Social work practice: Assessment, planning, intervention and review ( $3^{\text {rd }}$ ed.). Exeter: Learning Matters Ltd.

Payne, M. (2011). Humanistic social work: Core principles in practice. Basingstoke: Palgrave. 
Payne, M. (2014). Modern Social Work Theory ( $4^{\text {th }}$ ed.). Basingstoke: Macmillan.

Ritzer, G. (2004). The McDonaldization of society. London: Sage.

Ruch, G., Turney, D. and Ward, A. (2010). Relationship-based social work: getting to the heart of practice. London: Jessica Kingsley.

Sheppard, M. (1998). 'Practice validity, reflexivity and knowledge for social work'. British Journal of Social Work, 28, 763-781.

Steger, M. and Roy, R. (2010). Neoliberalism: A very short introduction. Oxford: Oxford University Press.

Sudbery, J. (2010). Human growth and development: An introduction for social workers. London: Routledge.

Taylor, C. and White, S. (2000). Practicing reflexivity in health and welfare: Making knowledge. Buckingham: Open University Press.

Therborn, G. (2013). The killing fields of inequality. Cambridge: Polity Press.

Thompson,N. (2006). Promoting workplace learning. Bristol: Policy Press.

Tracy, E.M. and Whittaker, J.K. (1990). The social network map. Families in Society, 71(8), 461-470.

Tsui, M. (2005). Social work supervision: Contexts and concepts. London: Sage.

White, M. and Epston, D. (1990). Narrative means to therapeutic ends. New York: Norton.

Wilkinson, R. and Pickett, K. (2010). The spirit level: Why equality is better for everyone. London: Penguin.

Winnicott, D. (1991). The child, the family and the outside world. Harmondsworth: Penguin.

Woolgar, S. (1988). Knowledge and reflexivity: New Frontiers in the sociology of knowledge. London: Sage. 